\section{As mudanças nas práticas de reabilitação profissional da Previdência Social no Brasil: modernização ou enfraquecimento da proteção social?}

\author{
Changes in workers' rehabilitation procedures \\ under the Brazilian social security system: \\ modernization or undermining \\ of social protection?
}

\footnotetext{
${ }_{1}$ Centro de Referência em Saúde do Trabalhador de Piracicaba, Piracicaba, Brasil.

2 Faculdade de Ciências Médicas, Universidade Estadual de Campinas, Campinas, Brasil

Correspondência A. M. Iguti

Departamento de Medicina Preventiva e Social, Faculdade de Ciências Médicas, Universidade Estadual de Campinas. C. P. 6111, Campinas, SP 13083-970, Brasil. iguti@fcm.unicamp.br
}

\begin{abstract}
This article describes the changes in workers' rehabilitation practices under the Brazilian National Social Security Institute (INSS) in the 1990 s, in the context of neoliberal economic adjustment measures, based on an analysis of INSS documents from 1992 to 1997. The INSS plan for "modernization" of workers' rehabilitation led to: (1) dismantling of multidisciplinary teams; (2) induction of workers to accept proportional retirement pensions and voluntary layoffs; (3) under-utilization of the remaining INSS professional staff; (4) elimination of treatment programs for workers' rehabilitation; and (5) dismantling of INSS rehabilitation centers and clinics. The changes in the Brazilian social security system undermined the county's social security project and hegemony and reduced social security reform to a mere management and fiscal issue. Current "rehabilitation" falls far short of the institution's original purpose of social protection for workers, while aiming at economic regulation of the system to contain costs of workers' benefits. Workers that suffer work-related accidents are denied occupational rehabilitation, which aggravates their social disadvantage when they return to work.
\end{abstract}

Social Security; Occupational Health; Rehabilitation
Mara Alice Batista Conti Takahashi 1

Aparecida Mari Iguti 2

\section{Introdução}

As diretrizes políticas e econômicas neoliberais, engendradas como enfrentamento à crise do capitalismo em escala mundial, traduziram-se, nos países adeptos, em medidas de governo voltadas para um ajuste estrutural que objetivou reduzir a despesa pública, pelo enxugamento do funcionalismo estável do Estado, através da extinção e privatização dos serviços sociais. O pensamento postulado é o de que o Estado deve deixar de ser o executor de algumas das políticas públicas para ser apenas seu agente regulador.

Do mesmo receituário, destacam-se outras medidas como: cortes em subsídios fiscais de interesse coletivo; modernização da estrutura produtiva, sobretudo industrial, pela disseminação de um novo padrão tecnológico e organizacional; e desregulamentação trabalhista para atender às demandas de flexibilização das empresas. Os principais impactos sociais apontados são: ampliação do desemprego, da precarização do trabalho e da concentração de renda; o enfraquecimento da representação sindical; e o desmonte da rede de proteção social 1 .

As instituições previdenciárias, notadamente nos países da América Latina, foram os alvos prioritários destas reformas. No Brasil, os serviços de reabilitação profissional da Previdência Social foram profundamente atingidos.

A reabilitação profissional brasileira caracteriza-se como uma política integrante do sistema 
de benefícios previdenciários, desenvolvida com exclusividade no âmbito do Estado, uma resposta pública à questão da incapacidade associada aos acidentes de trabalho e às doenças profissionais.

A prática de reabilitação profissional é genericamente definida por Seyfried ${ }^{2}$ como um programa de intervenção estruturado para desenvolver atividades terapêuticas e de profissionalização que abrangem a totalidade dos indivíduos e os fortalece para lidar e superar as dificuldades impostas por suas incapacidades. Seus objetivos visam à estabilização física e psicossocial e possibilitam a reintegração nas relações sociais, cotidianas e de trabalho. Para o autor, o objetivo de um programa de reabilitação profissional só é alcançado quando o seu resultado é a inserção da pessoa em um trabalho que permita sua integração social plena.

A prestação dos serviços de reabilitação profissional articulada aos sistemas de previdência social tem um duplo papel: se, por um lado, são formas de intervenção para a redução e a superação das desvantagens produzidas pelas incapacidades, são, por outro, também estratégias de regulação econômica destes sistemas com a finalidade de reduzir o tempo de concessão de benefícios previdenciários 3 .

O objetivo deste estudo é descrever as mudanças ocorridas nas práticas de reabilitação profissional do Instituto Nacional do Seguro Social (INSS) e no cotidiano dos serviços, na década de 1990, e analisá-las a partir de sua contextualização com as medidas neoliberais das reformas brasileiras - administrativa e previdenciária.

\section{Breve histórico}

No Brasil, o acesso aos serviços previdenciários configurou-se, desde seus primórdios, como um direito trabalhista das classes assalariadas urbanas. Com características administrativas e técnicas de seguro social, os serviços encarregados da proteção social brasileira desenvolveram práticas arraigadas à concepção de "cidadania regulada", ou seja, os direitos de assistência médica, pensões e aposentadorias estiveram vinculados ao contrato compulsório dos trabalhadores do setor privado com o seguro gerenciado pelo Estado, mas na dependência da inserção formal no mercado de trabalho. Este seguro, que inicialmente ficou restrito a alguns setores da economia, era coberto pelas Caixas de Aposentadorias e Pensões (CAPs) e pelos Institutos de Aposentadorias e Pensões (IAPs) e posteriormente unificado no Instituto Nacional de Previdência Social (INPS) 4.

A prática de reabilitação profissional na Previdência Social foi instituída nas CAPs e IAPs em
1943, no governo Vargas 5, no entanto, tornou-se uma obrigação legal apenas em 1967, no INPS, com a estatização do Seguro do Acidente de Trabalho (SAT) garantindo, pela primeira vez, uma fonte de custeio permanente para a área 6 .

O projeto de implantação dos Centros de Reabilitação Profissional do INPS (CRPs) foi orientado por uma concepção de excelência, afinada com a tendência hospitalocêntrica da assistência médica vigente na época, na qual se disponibilizavam todos os recursos terapêuticos necessários no interior dos próprios serviços, com grandes estruturas físicas, equipamentos de fisioterapia e terapia ocupacional de alto custo e um grande contingente de profissionais. Os Núcleos de Reabilitação Profissional do INPS (NRPs) eram unidades menores, com uma ou duas equipes que referenciavam para os CRPs os casos de maior complexidade.

A área de reabilitação profissional da Previdência Social, na década de 1970, concentrou o maior volume de recursos do instituto - equipamentos, financeiros e de pessoal técnico especializado de maior faixa salarial 7 .

O modelo de atenção convencional desses serviços era desenvolvido por equipes multiprofissionais formadas por médicos, assistentes sociais, psicólogos, fisioterapeutas, terapeutas ocupacionais, enfermeiros, fonoaudiólogos, pedagogos e sociólogos. As atividades de profissionalização eram desenvolvidas através de um quadro especializado de professores de ofício e de programas de alfabetização com classes de ensino básico.

Os CRPs e NRPs atendiam a uma clientela importante de trabalhadores amputados por acidentes de trabalho, contando com um sistema de apoio técnico e logístico de avaliação, prescrição e aquisição de órteses e próteses.

Na década de 1980, houve a expansão da rede nacional para todas as capitais dos estados e também para algumas cidades de grande porte, tendo como critérios principais de implantação a magnitude dos acidentados de trabalho com concessão de benefícios e a existência de recursos universitários formadores de pessoal técnico. Os serviços tinham abrangência regional e seus usuários ficavam, em média, 240 dias em programa, tendo as despesas com transporte, alimentação, hospedagem, documentação, medicamentos, cursos profissionalizantes e instrumentos de trabalho, custeadas pela Previdência Social.

No entanto, no decorrer desta mesma década, devido à falta de investimentos do governo, os CRPs e NRPs tiveram suas instalações físicas sucateadas, com uma brutal carência de recursos humanos, intensificada na década de 1990, pela adesão dos profissionais aos planos de aposenta- 
doria proporcional e pelos incentivos do governo à demissão, os planos de demissão voluntária, comprometendo os índices de resolutividade e cobertura de suas intervenções técnicas.

Em levantamento realizado em 1993, havia no Brasil quarenta e seis serviços de reabilitação profissional, sendo 21 CRPs e 25 NRPs. Em 1994, a rede nacional contava apenas com 2.122 profissionais, sendo 848 de nível médio e 1.274 de nível superior 8 .

Na década de 2000, houve a total desativação dos CRPs e NRPs e a transformação do modelo de atenção de reabilitação profissional no Programa Reabilita, um subprograma das perícias médicas das agências de benefícios da Previdência Social.

\section{Metodologia}

Partindo do pressuposto de que os documentos institucionais oficiais, que embasam as práticas sociais nos serviços, não são puramente técnicos e nem anistóricos 9, mas se configuram como instrumentos essenciais de realização de projetos políticos, esta pesquisa documental investigou relatórios, memorandos, circulares, ordens de serviço e resoluções do INSS de 1992-1997. Nesse período, a primeira autora estava na chefia do CRP-Campinas e vivenciou as mudanças reformistas da Previdência Social de que trata este artigo, que foram analisadas em sua tese de doutorado, sob orientação da segunda autora 10 .

O período escolhido corresponde à gestação e implementação da reforma do Estado brasileiro dos anos 1990, possibilitando evidenciar algumas das principais características do modelo político neoliberal adotado pelo governo da época 11.

Segundo Gonzaga 12 os documentos normativos do INSS estão muito próximos das atividades dos profissionais dos serviços, que com eles convivem diariamente, e, portanto, têm um valor institucional interno significativo, pois contêm o detalhamento das Leis, Decretos e Portarias do governo, de modo a consubstanciar as decisões tomadas.

Os memorandos, circulares e ordens de serviço (atualmente substituídas por instruções normativas) destinam-se a marcar a posição das chefias na abordagem de assuntos e tópicos específicos. As resoluções têm as mesmas características, porém são emitidas pelo presidente do órgão, regulando matéria de sua competência 12 .

Esses documentos institucionais de circulação interna representam, em última análise, a interpretação das hierarquias no poder sobre o conteúdo técnico e político da legislação previdenciária, bem como os circulados pelo Minis- tério da Reforma do Estado, datados do mesmo período.

Desta forma, eles não são quaisquer registros que ficam no passado, mas são produtos sociais elaborados conforme as forças que detêm o poder em determinado tempo e local 13 .

A apresentação dos resultados e a análise seguiram a ordem cronológica de expedição e circulação dos documentos, buscando identificar a historicidade dessas normatizações com os projetos políticos e ideológicos em curso.

\section{Resultados}

Para dar respostas aos questionamentos sociais dinamizados pelo processo de redemocratização do país após duas décadas de ditadura militar, tendo na elaboração da Constituição Federal de 1988 um importante marco político e social, o governo brasileiro instituiu, em 1992, grupos de trabalho que tinham como temática de estudo a saúde do trabalhador no Brasil, dividida em quatro subtemas: prevenção, assistência à saúde, assistência previdenciária e sistema de informação.

No grupo de trabalho da assistência previdenciária, a reabilitação profissional do INSS foi veementemente criticada em seu modelo de atenção, considerado "ultrapassado, centralizado, inadequado e com desempenho não satisfatório" (Relatório do grupo de trabalho/assistência previdenciária em acidentes de trabalho. Brasília: Instituto Nacional de Previdência Social; 1992).

Os diagnósticos resultantes dos quatro subgrupos foram consolidados por uma Comissão Interministerial de Saúde do Trabalhador, instituída pela Portaria $n^{\circ} .1$ de 20 de abril de 199314 e formada por especialistas com experiência e reconhecida qualificação acadêmica, que tiveram como tarefa elaborar um diagnóstico geral mais abrangente e propor técnicas de integração entre as políticas e as práticas dos três Ministérios - Saúde, Previdência e Trabalho - para o equacionamento dos problemas diagnosticados.

O relatório final da comissão concluiu que " $a$ situação de saúde dos trabalhadores no Brasil não reflete uma condição de cidadania plena (...) e o trabalho é, para muitos, fonte de morte, mutilações, doenças, desgaste ou sofrimento" (Relatório final da Comissão Interministerial de Saúde do Trabalhador. Brasília: Instituto Nacional de Previdência Social; 1993).

As consistentes propostas técnicas formuladas pela comissão desdobraram-se, de imediato, em medidas administrativas positivas na direção do equacionamento dos problemas identificados nos serviços de reabilitação profissional 
e perícia médica do INSS: (1) a formalização do Núcleo de Referência em Doenças Ocupacionais da Previdência Social de Belo Horizonte, Minas Gerais, Brasil, como assessoria técnica na emissão de pareceres de nexo-causal de acidentes de trabalho e doenças profissionais e na elaboração de normas técnicas periciais para a avaliação da incapacidade para o trabalho (Resolução INSS $n^{\circ}$. 142. Instituto Nacional de Previdência Social 1993; 16 abr); (2) a obrigatoriedade da vistoria no local de trabalho pelos médicos peritos para o reconhecimento do nexo-causal das doenças ocupacionais; (3) a afirmação da comunicação do acidente de trabalho como instrumento de notificação compulsória por parte da empresa, mas, nos casos de sua omissão, a sua emissão era facultada ao médico-assistente, ao sindicato, aos serviços de saúde pública e ao próprio acidentado/adoecido e seus familiares, com obrigatoriedade de registro pelo INSS; (4) a atribuição da perícia médica do INSS em repassar os dados e informações aos demais órgãos públicos envolvidos na atenção à saúde do trabalhador, como a Delegacia Regional do Trabalho e a vigilância sanitária do Sistema Único de Saúde (SUS) para a formulação de diagnósticos epidemiológicos; (5) o estímulo às parcerias interinstitucionais (Ordem de serviço INSS no. 329. Instituto Nacional de Previdência Social 1993; 26 out).

Pode-se assinalar ainda, como desdobramento dos trabalhos da Comissão Interministerial de Saúde do Trabalhador, a avançada proposta do coordenador dos serviços previdenciários do INSS, Dr. Ricardo Akel, de criação do Centro Integrado de Atenção em Saúde do Trabalhador: "um espaço de ação integrada entre a Previdência Social, o Ministério do Trabalho e o SUS, um condomínio de serviços públicos afinados, onde cada instituição conserva sua vinculação, natureza e autonomia, mas trabalha de forma integrada com as demais" (Memorando circular $\mathrm{n}^{\circ}$. 18. Instituto Nacional de Previdência Social 1993; 16 nov). Esta proposta, apesar de derrotada na época, dada sua relevância social, ressurge 12 anos depois, com nova roupagem, mas mantendo sua essência, na III Conferência Nacional de Saúde do Trabalhador, realizada em novembro de 200515.

Contudo, apesar de os ares constitucionais ensejarem mudanças positivas e criarem um espaço político mais favorável ao surgimento de projetos inovadores no interior dos serviços, no II Seminário de Atividades Previdenciárias, realizado em Brasília em 1994, que foi um locus importante de disputa política, saiu vencedora a decisão de que a reabilitação profissional era um benefício da Previdência Social e não um serviço de saúde, condicionado à contribuição dos segurados, não devendo ter seu acesso universalizado. No debate, foi rejeitada a proposta de transferência da rede nacional de reabilitação profissional do INSS para o SUS (Relatório final do II Seminário de Atividades Previdenciárias. Brasília: Instituto Nacional de Previdência Social; 1994).

No ano seguinte, 1995, documentos enviados pelo Ministério da Reforma do Estado começaram a circular regularmente no interior dos CRPs e NRPs, fazendo a crítica ao modelo gerencial estatal e propondo sua "modernização" 16 . A estabilidade dos servidores públicos aparecia como alvo principal das críticas: "As relações de trabalho no setor público estão engessadas pelo caráter protecionista da legislação, o que tem um efeito inibidor do espírito empreendedor, como por exemplo, a aplicação indiscriminada da estabilidade para o conjunto dos servidores, os critérios rígidos de seleção e contratação de pessoal que impedem o recrutamento direto no mercado, em detrimento do estímulo à competência. A estabilidade faz com que os servidores não valorizem seus empregos $e$ os administradores ficam sem instrumentos para motivar seus funcionários" 16 (grifos nossos).

A estabilidade, no discurso ministerial, era vista como uma "camisa-de-força", que condicionava o funcionário a permanecer no serviço público, fazendo com que ele recusasse melhores oportunidades de trabalho no setor privado, "motivado por sentimentos de insegurança, irracionais e doentios, que não caberia ao Estado resolver" 16 .

A solução: a quebra da estabilidade adquirida por concurso público. "Quando a pessoa se torna desnecessária por excesso de quadros ou desmotivada com seu trabalho, ela seria dispensada, mas indenizada correspondentemente. Nos anos 60 , quando a estabilidade do setor privado foi substituída pelo Fundo de Garantia por Tempo de Serviço (FGTS), os opositores diziam que o mundo desabaria sobre os trabalhadores, no entanto, isto não aconteceu, as empresas, com esta medida, ganharam mais racionalidade e eficiência e os trabalhadores passaram a ser racionalmente protegidos pelo FGTS" 16 (grifo nosso).

As agências autônomas (Organização Social de Interesse Público, na versão atual), foram apresentadas como estratégias da reforma administrativa, pois operariam no setor de serviços sociais do Estado, executando políticas públicas, mas com a gestão "flexibilizada", sem a "rigidez" do modelo burocrático estatal: (1) possibilidade de contratação temporária de funcionários, de acordo com as necessidades designadas nos contratos de gestão com o governo, eliminando-se o concurso público como regra generalizada de in- 
gresso no serviço público; (2) incentivos de promoção voltados para os resultados, para as metas do contrato de gestão. A criação de um bônus de resultado, uma recompensa equivalente aos adicionais de participação de lucros das empresas privadas, que pode ser alcançado individualmente ou por equipe, suprimindo os incentivos tradicionais do serviço público de assiduidade, tempo de serviço e instrução formal, concedidos de forma igualitária; (3) quebra da estabilidade após dois anos de efetivo exercício (estágio probatório), abrindo a possibilidade de demissão para enxugamento de quadros ou por "insuficiência individual de desempenho”; (4) a quebra das regras de licitação para a operacionalização de verbas públicas, através de regulamentos mais flexíveis, estipulados de comum acordo nos contratos de gestão.

Os resultados apontados seriam: (1) redução dos gastos públicos; (2) racionalização dos processos de trabalho; (3) melhoria da eficiência da administração pública com a eliminação dos desperdícios; (4) a satisfação dos clientes como parâmetro de avaliação da qualidade dos serviços.

A reforma administrativa britânica, realizada pela gestão da Primeira Ministra Margareth Thatcher, que resultou na redução de 700 mil servidores do Civil Service para 500 mil, era citada como exemplo, porque teria trazido competitividade e "eficiência" aos serviços públicos ingleses: "A reforma brasileira deve levar a um aumento da eficiência, mas, assim como ocorreu na reforma britânica e ocorre no setor privado, poderá levar a uma redução no quadro de pessoal. Há, portanto, um trade-off entre o nível de emprego do Setor Público e o nível de eficiência. E o trade-off não é um argumento suficientemente consistente para rejeitar a Reforma. A Reforma deve ser vista como uma extensão dos processos de modernização da economia, que decorrem basicamente do processo tecnológico, da competição em escala global, dos padrões exigentes do consumidor e das mudanças na gerência do setor público e privado em todo o mundo" 17 (p. 18).

Para a elaboração do plano de reforma da máquina previdenciária foi contratada a assessoria da Fundação Instituto de Administração, da Universidade de São Paulo, que definiu como objetivos específicos quatro grandes eixos: (1) a melhoria da qualidade dos serviços prestados; (2) o aumento da arrecadação previdenciária; (3) a redução dos custos operacionais; (4) a diminuição na ocorrência de erros e fraudes.

A seguir, a imagem-objetivo do trabalho apresentada pela consultora: "Uma seguradora de grande porte e âmbito nacional, bem avaliada quanto aos serviços prestados aos seus clientes, apoiada em um sistema de gestão ágil, confiável e seguro nas respostas, com pessoas preparadas, integradas e comprometidas com a alta qualidade do atendimento, utilizando intensamente a informatização, com uma situação econômico-financeira equilibrada" 18 (p. 3).

Paralelamente aos documentos apologistas da quebra do direito à estabilidade e da transformação dos serviços sociais públicos em agências autônomas, os documentos de circulação interna traziam questionamentos quanto ao destino da reabilitação profissional no INSS, instalando um clima de insegurança emocional no cotidiano dos serviços, porém, ao mesmo tempo, aventavam propostas de reformulação que, supostamente, garantiriam a permanência dos servidores e dos serviços.

As propostas estavam essencialmente direcionadas ao redimensionamento dos serviços através de medidas de ajustamento à situação de enxugamento dos quadros e carência dos recursos terapêuticos. A criação das equipes volantes e das equipes de extensão representou a primeira mudança importante no modelo técnico assistencial dos CRPs e NRPs, abalando a concepção tradicional de equipes multiprofissionais.

As equipes volantes, apesar de chamadas de equipes, eram, na prática, duplas formadas por um médico e qualquer profissional de nível universitário, denominado orientador profissional, que se deslocariam dos serviços para prestar atendimento nas diversas agências de Previdência Social de sua área de abrangência regional.

As equipes de extensão também eram duplas de composição semelhante à anterior, mas formadas por médicos peritos e assistentes sociais das próprias agências. Com isto, foram aproveitados servidores transferidos de outros órgãos públicos extintos, como a Legião Brasileira de Assistência, que passaram a executar atividades de reabilitação profissional com a "supervisão" (à distância) dos CRPs e NRPs (Memorando circular $\mathrm{n}^{\circ}$. 13. Instituto Nacional de Previdência Social 1994; 9 jan).

Foram estabelecidas, pela primeira vez, metas quantitativas para os serviços de reabilitação profissional, condicionando a essa produção a permanência dos serviços. A meta nacional estabelecida pela chefia geral, para o ano de 1995, foi de 20 mil segurados reabilitados, $37 \%$ a mais do que os resultados obtidos em 1994, para a qual foram conclamados todos os servidores da área a "envidar esforços no sentido de alcançá-la" (Memorando circular $n^{\circ}$. 13. Instituto Nacional de Previdência Social 1994; 9 jan).

Tais metas exerceram forte pressão nos serviços, incentivando o desmantelamento das equipes multiprofissionais tradicionais e a adesão a uma nova modalidade de "equipe", a exemplo 
das equipes volantes e de extensão, formada pela dupla - médico e orientador profissional. Os serviços que se adequaram estavam conseguindo atender, por dupla, cinqüenta segurados/mês e eram citados como exemplos bem-sucedidos, uma vez que haviam triplicado o número mensal de segurados atendidos (Memorando circular no. 06. Instituto Nacional de Previdência Social 1995; 6 ago).

Alguns serviços, contudo, resistiram às mudanças, e as orientações das hierarquias superiores para as chefias locais eram de que estas se empenhassem mais na "identificação dos fatores geradores de desmotivação dos servidores para com as mudanças", ao mesmo tempo em que se colocava a implementação de mudanças institucionais-legais, “como a oficialização da carreira do orientador profissional e as alterações da Lei $n^{\circ} .8 .213$ referentes à missão e às atribuições da reabilitação profissional", como instrumentos impositivos para os profissionais que resistiam em se adequar às mudanças propostas (Memorando circular $n^{\circ}$. 08. Instituto Nacional de Previdência Social 1995; 9 nov).

Os documentos apresentavam um forte apelo ao voluntarismo dos profissionais: "A necessidade de mudança de cultura interna (...) de fomento ao desenvolvimento de uma mentalidade participativa, compromissada e criativa, buscando a valorização do serviço não somente pelos próprios servidores, mas também pelos usuários, pela Previdência Social e pela sociedade em geral" (Memorando circular $n^{\circ}$. 03. Instituto Nacional de Previdência Social 1993; 15 mar).

"As perspectivas mais alvissareiras para o ano de 1996, ainda que continuem algumas dificuldades, principalmente em relação à carência de recursos humanos em algumas unidades executivas, [referindo-se àquelas que não haviam desmantelado suas equipes multiprofissionais] $o$ que exige de todos nós maior vinculação, interesse, dedicação, sabedoria, capacidade e vontade de promover e desenvolver as ações de reabilitação profissional com eficiência e eficácia, buscando a efetividade dos resultados, a valorização do serviço e a satisfação profissional" (Memorando circular no. 01. Instituto Nacional de Previdência Social 1996; $12 \mathrm{fev})$.

No mesmo período de implantação dessas mudanças, o então coordenador das atividades previdenciárias do INSS, Dr. Baldur Schubert, elaborou um documento que criticava o sistema brasileiro como omisso e ineficiente no manejo dos acidentes de trabalho e doenças profissionais, apropriando-se dos diagnósticos elaborados pelos grupos de trabalho e da Comissão Interinstitucional de Saúde do Trabalhador, porém, propondo uma solução diferente: a priva- tização do SAT e a transferência dos serviços de reabilitação profissional para as mútuas (organizações privadas, sem fins lucrativos, que atuariam como agências autônomas) ou seguradoras privadas 19 .

Em campanha nacional, do Norte ao Sul do país, o coordenador buscou a adesão de sindicalistas, profissionais de saúde, cooperativas médicas, dirigentes de fundos de pensão e de planos privados de saúde ao seu projeto, ancorado na identificação de quatro problemas principais 19 (p. 10): - A omissão do INSS nas atividades de promoção à saúde e de prevenção dos acidentes de trabalho e doenças profissionais: "o segurador (INSS) é essencialmente um pagador de benefícios pecuniários post-factum, prestados à guisa de reparação";

- As dificuldades de caracterização das doenças profissionais cujo "nexo causal é eminentemente epidemiológico, cada vez mais amplo, ubíquo e complexo". Segundo o documento, a conseqüência dessa dificuldade seria a transferência das decisões para a esfera jurídica, de andamento longo e oneroso, com intervenção nem sempre oportuna de advogados e peritos judiciais;

- Os conflitos ocasionados pela diferença entre as lógicas das instituições que têm interface com a questão dos acidentes de trabalho e das doenças profissionais: "a do Seguro, que necessita da certeza (...) da incapacidade para o trabalho de seus segurados, a da Saúde, que privilegia o diagnóstico e o tratamento dos pacientes e a da Vigilância, que se preocupa em afastar os trabalhadores expostos das fontes de exposição, o mais precocemente possível, valorizando manifestações subclínicas (...) ainda que inespecíficas" (grifos do documento);

- A baixa capitalização da experiência da reabilitação profissional: " $a$ valiosa experiência do INSS em trabalhar na reabilitação profissional dos acidentados de trabalho, preparando-os para a reinserção no trabalho, é quantitativamente insuficiente" (grifo nosso).

As soluções viriam com a constituição de um novo modelo de gerenciamento doSAT embasado "na experiência internacional acumulada nessa área”,constituídodasseguintespropostas ${ }^{19}$ (p.11): - "Enfoque preventivo: o novo SAT deve enfocar a prevenção dos danos e a promoção de condições saudáveis de trabalho, reorientando o processo atual, centralizado na reparação";

- "Integralidade: o conjunto das atividades preventivas, de assistência à saúde, reabilitação profissional, serviço social e pagamento de benefícios que são devidos a todo segurado e que deverão ser prestados de forma global";

- "Gestão diferenciada: modelo misto de gestão, com a participação estatal no controle e na super- 
visão e a operacionalização por organizações de independência administrativa";

- "Ampla participação onde o SAT deve ser gerido por empregadores e empregados, através da criação de entidades privadas, sem fins lucrativos, cujos integrantes são solidários entre si e com autonomia de gestão. Como seriam entidades de gestão privada com recursos públicos, sua concessão ficaria a cargo do poder público. O Estado, no caso representado pelo MPAS/INSS, deveria assumir o papel de coordenador, fiscalizador e avaliador $e$ não de executor".

O enfoque do documento estava na criação de mútuas, entidades sem fins lucrativos, que seriam responsáveis pela atenção aos acidentados de trabalho, porém, concorrendo com as seguradoras privadas: “(...) os sistemas montados por empresários e empregados (mútuas) atendem aos interesses de patrões e trabalhadores, diminuem os conflitos e as tensões sociais; são descentralizados, cooperativos (entidades colaboradoras) com a Previdência Social e competitivos entre si; modelo exitoso em inúmeros países, aceito como justo socialmente, de custo relativamente baixo e efetivo em termos de redução da sinistralidade, pelo seu enfoque preventivo e de grande participação social" 19 (p. 12).

"O SAT, por meio das mútuas, abordaria o segurado na integralidade, isto é, proporcionaria ações de prevenção, reabilitação em seu sentido amplo, desde a assistência médica até a reabilitação profissional e social, e compensação financeira (auxílios, aposentadorias e pensões)" 19 (p. 12).

A privatização do SAT traria mudanças também na arrecadação do seguro, pois estabeleceria mecanismos de estímulo à prevenção, recompensando as empresas que investissem em prevenção e penalizando as que se omitissem, fiscalizadas através dos seus índices de sinistralidade: "A tarifação individual (por empresa) consideraria uma parte fixa em função do risco da atividade econômica e uma variável de acordo com o desempenho (sinistralidade) e o plano de investimentos da empresa, acoplado ao sistema bonus/malus. A conseqüência seria a redução ou o aumento das alíquotas de contribuição de acordo com o desempenho" 19 (p. 12).

No final de 1996, "70\% dos CRP(s) (14 dos 21 existentes) e $3 \mathrm{NRP}(\mathrm{s})$ (de um total de 25) funcionavam com a nova estrutura. As Equipes de Extensão estavam em funcionamento em doze estadose as Equipes Volantes prestavam serviços em $17 \%$ dos Postos de Seguro Social do INSS em todo país" (Relatório da Divisão Nacional de Reabilitação Profissional de 30 de novembro de 1996. Brasília: Instituto Nacional de Previdência Social; 1996).

A oficialização da nova estrutura funcional da reabilitação profissional ocorreu em 7 de março de 1997, através do Decreto $n^{o} .2 .172$ 20, do Ministério da Previdência Social, de 06 de março de 1997, e foi normatizada por duas resoluções. A primeira desmontava os CRPs e NRPs, descentralizando os serviços de reabilitação profissional para as agências de benefícios do INSS (Resolução no. 423/MPAS/INSS. Instituto Nacional de Previdência Social 1997; 7 mar). A segunda alterava as funções básicas do processo de reabilitação profissional para: (1) a avaliação e a definição da capacidade laborativa; (2) a orientação e o acompanhamento do programa profissional; (3) a articulação com a comunidade para reingresso no mercado de trabalho e (4) o acompanhamento e a pesquisa de fixação no mercado de trabalho (Resolução no. 424/MPAS/INSS. Instituto Nacional de Previdência Social 1997; 7 mar).

\section{Discussão e conclusão}

A redemocratização política do Brasil do final dos anos 1980 teve a mobilização da sociedade pela conquista da saúde como um direito de todos e um dever do Estado.

O movimento social, denominado Reforma Sanitária, culminou com a criação do SUS em 1990, um sistema de saúde essencialmente público e baseado no princípio da universalidade do acesso, representando uma ruptura com o modelo de assistência médica de compra pelo Estado de serviços privados prestados exclusivamente aos trabalhadores do mercado de trabalho formal.

A instituição constitucional da seguridade social, em 1988, apontou para a necessidade de transformação da Previdência Social, igualmente fundamentada em princípios como a universalidade do acesso, a integralidade da atenção a todos os riscos sociais, a irredutibilidade dos valores de benefícios, a solidariedade no financiamento através do orçamento fiscal da União e o controle social dos trabalhadores.

A análise mostrou que, após um breve período de influência dos ares constitucionais progressistas, o modelo previdenciário de seguro social tornou-se hegemônico, com uma série de mudanças na organização dos serviços e na conduta de concessão de benefícios pelo INSS, organicamente vinculadas às diretrizes macropolíticas e macroeconômicas neoliberais de redução das políticas públicas.

As medidas administrativas do Plano de Modernização da Reabilitação Profissional do INSS foram respaldadas no ideário de flexibilização, enxugamento e eficiência das "novas" políticas de gestão, que não são novas em seus fundamentos, mas que, nos anos 1990, conseguiram 
se impor de tal forma que se transformaram em práticas das organizações 21 .

As estratégias utilizadas para a adesão dos profissionais à reforma foram semelhantes às formas de gestão dos recursos humanos das empresas privadas após a reestruturação produtiva capitalista: (1) definição pelas hierarquias superiores de metas intencionalmente utópicas; (2) promessa da permanência dos CRPs e NRPs pelo aumento da cobertura e agilização dos programas no cumprimento dessas metas e (3) os apelos ao voluntarismo dos profissionais, como se a eficiência dos serviços dependesse exclusivamente das atitudes pessoais de engajamento, descoladas das condições reais de trabalho, que apresentavam um avançado sucateamento das instalações físicas e dos equipamentos e uma acentuada defasagem de pessoal.

A adesão, todavia, não garantiu a permanência dos CRPs e NRPs, como era a expectativa geral induzida. As mudanças apresentadas como medidas meramente organizativas e gerenciais afetaram profundamente o conteúdo e a oferta dos serviços de reabilitação profissional: o desmantelamento do modelo tradicional de atenção em equipes multiprofissionais, reconhecido internacionalmente como o mais adequado para a intervenção com pessoas com incapacidades, a supressão total das atividades terapêuticas e de profissionalização e a subutilização da capacidade técnica de assistentes sociais, psicólogos, sociólogos, fisioterapeutas e terapeutas ocupacionais, homogeneizados pela figura do orientador profissional.

As reformas da Previdência Social, ocorridas no Brasil na década de 1990 e avançadas pelos anos 2000, não equacionaram os principais problemas diagnosticados pela Comissão Interministerial de Saúde do Trabalhador de 1993: os segurados continuam sendo tratados como não-cidadãos, a classe trabalhadora continua morrendo, sendo mutilada e adoecida pelo trabalho, e as instituições públicas que fazem interface com a saúde do trabalhador - Ministério da Saúde, Ministério da Previdência Social e Ministério do
Trabalho - continuam desarticuladas e com baixo poder de intervenção diante do poderio das empresas. A ineficiência brasileira no manejo dos acidentes de trabalho e das doenças profissionais é uma realidade que cotidianamente se atualiza, agravada pelas condutas do INSS de contenção da permanência dos trabalhadores incapacitados nos programas de suporte de renda sem lhes ter ofertado a possibilidade de superação de suas desvantagens através de programas de reabilitação profissional.

Desta forma, como afirma Silva 22, a defesa da Previdência Social solidária no Brasil, de gestão pública, democrática e universal, significa postular muito mais do que ela se apresenta hoje: (1) significa uma profunda revisão dos atuais métodos gerenciais, concebidos sob os fundamentos do seguro social - regime de capitalização que utiliza estratégias tipicamente mercantis para manter sua rentabilidade, tais como, a seleção de riscos de menor custo, a recusa de certos riscos e a transferência de riscos e prejuízos para os segurados; (2) significa a melhoria da máquina previdenciária orientada pelo caráter distributivo essencial de sua existência e pela garantia dos direitos sociais como fundamentos de suas funções e atribuições.

Legitima-se assim a Previdência Social pública como o mais promissor mecanismo de articulação entre a economia e a sociedade na promoção do desenvolvimento, lembrando o que a história já demonstrou, exaustivamente, que o aumento do estoque de capital de um país não representa necessariamente melhoria das condições de vida e bem estar social 22.

A proposta que seguimos acreditando é a de um pacto de nação pela seguridade social, ancorado no princípio da solidariedade e financiado pelos recursos dos impostos pagos pela sociedade, afirmativo do direito à proteção social pelo Estado para todas as pessoas que, temporária ou permanentemente, forem atingidas em sua capacidade de trabalho, com critérios técnicos de acesso abrangentes e justos e com controle social dos trabalhadores. 


\section{Resumo}

O presente artigo descreve as mudanças ocorridas nas práticas de reabilitação profissional do Instituto Nacional do Seguro Social (INSS) na década de 1990, contextualizadas com as medidas neoliberais de ajuste econômico, investigada através de documentos operacionais do INSS de 1992 a 1997. O plano de "modernização" da reabilitação profissional do INSS trouxe os seguintes resultados: (1) desmantelamento das equipes multiprofissionais; (2) indução dos seus profissionais a aposentadoria proporcional e aos Planos de Demissão Voluntária; (3) sub-utilização dos profissionais remanescentes; (4) eliminação dos programas terapêuticos de reabilitação profissional e (5) desmonte dos centros e núcleos de reabilitação profissional do Instituto Nacional de Previdência Social (INPS). As mudanças na Previdência Social do Brasil traduzem o enfraquecimento do projeto nacional de Seguridade Social, a hegemonia do projeto de Seguro Social e a redução da reforma previdenciária a uma questão de natureza gerencial e fiscal. As práticas atuais de "reabilitação" estão distanciadas da finalidade institucional de proteção social dos trabalhadores e objetivam a regulação econômica do sistema pela contenção de despesas com benefícios. Os segurados acidentados e adoecidos do trabalho estão desassistidos de reabilitação profissional, o que aumenta a sua desvantagem social por ocasião do retorno ao trabalho.

Previdência Social; Saúde do Trabalhador; Reabilitação

\section{Referências}

1. Oliveira CAB, Mattoso JEL, organizadores. Crise e trabalho no Brasil: modernidade ou volta ao passado? São Paulo: Editora Scritta; 1996.

2. Seyfried E. Vocational rehabilitation and employment support services. In: Disability and Work Encyclopedia of Occupational Health and Safety [CD-ROM]. Geneva: International Labour Organization; 1998.

3. Momm W, Geicker O. Disability: concepts and definitions. In: Disability and Work. Encyclopedia of Occupational Health and Safety [CD-ROM]. Geneva: International Labour Organization; 1998.

4. Cohn A. A saúde na Previdência Social e na seguridade social, antigos estigmas e novos desafios. In: Cohn A, Elias P, organizadores. Saúde no Brasil: políticas e organização de serviços. São Paulo: Cortez Editora; 1996. p. 11-55.

5. Soares LBT. Terapia ocupacional lógica do capital ou do trabalho? São Paulo: Editora Hucitec; 1991.

\section{Colaboradores}

M. A. B. C. Takahashi trabalhou na redação do artigo. A. M. Iguti colaborou na revisão, correção e orientação da elaboração do artigo.
6. Hennington EA. Saúde e trabalho: considerações sobre as mudanças na legislação acidentária brasileira e sua influência sobre a classe trabalhadora [Dissertação de Mestrado]. Campinas: Universidade Estadual de Campinas; 1996.

7. Ferreira IM. Reabilitação profissional e serviço social. São Paulo: Cortez Editora; 1985.

8. Takahashi MABC. Avaliação em reabilitação profissional: a experiência de adoecer por LER e o resgate da autonomia: uma trajetória singular [Dissertação de Mestrado]. Campinas: Universidade Estadual de Campinas; 2000.

9. Merhy EE. O capitalismo e a saúde pública. Campinas: Editora Papirus; 1987.

10. Takahashi MABC. Incapacidade e Previdência Social: trajetória de incapacitação de trabalhadores adoecidos por LER/DORT no contexto da reforma previdenciária brasileira da década de 1990 [Tese de Doutorado]. Campinas: Universidade Estadual de Campinas; 2006. 
11. Soares LT. Os custos sociais do ajuste neoliberal na América Latina. São Paulo: Cortez Editora; 2000. (Coleção Questões da Nossa Época, 78).

12. Gonzaga P. Perícia médica da Previdência Social. São Paulo: Editora LTr; 2001.

13. Le Goff J. História e memória. Campinas: Editora da Universidade Estadual de Campinas; 1994.

14. Ministério da Previdência Social/Ministério da Saúde/Ministério do Trabalho. Portaria interministerial no. 1. Diário Oficial da União 1993; 23 abr.

15. Ministério da Saúde. Propostas da III Conferência Nacional em Saúde do Trabalhador. Brasília: Ministério da Saúde; 2005.

16. Ministério da Reforma do Estado. Reforma administrativa e previdenciária. Brasília: Ministério da Reforma do Estado; 1995.

17. Nunes MA. Agências autônomas: projeto de reforma administrativa das autarquias e fundações públicas federais do setor de atividades exclusivas do Estado. Brasília: Ministério da Reforma do Estado; 1996.
18. Fundação Instituto de Administração, Universidade de São Paulo. Revisão organizacional do INSS. São Paulo: Fundação Instituto de Administração, Universidade de São Paulo; 1997.

19. Schubert B. Considerações sobre o acidente de trabalho no Brasil. Brasília: Instituto Nacional da Previdência Social; 1996.

20. Ministério da Previdência Social. Decreto $n^{\circ} .2 .172$ Diário Oficial da União 1997; 6 mar.

21. Lima MEA. Os equívocos da excelência: as novas formas de sedução na empresa. Petrópolis: Editora Vozes; 1996.

22. Silva AA. A reforma da Previdência Social brasileira: entre o direito social e o mercado. São Paulo Perspect 2004; 18:16-32.

Recebido em 16/Ago/2007

Versão final reapresentado em 13/Mar/2008

Aprovado em 15/Abr/2008 